\title{
Knowledge, Opinions and attitudes towards HIV and AIDS among Youth in Botswana
}

Majelantle RG*, Keetile M, Bainame K and Nkawana P

Department of Population Studies, University of Botswana, Gaborone, Botswana

\begin{abstract}
Knowledge, opinions and attitudes of youth towards HIVIAIDS are very important for HIVIAIDS prevention, care and support. Botswana is one of the countries in sub Saharan Africa which has long struggled with HIVI AIDS epidemic and several program efforts aimed at enhancing knowledge about HIVIAIDS have been developed and implemented. The current paper utilizes data derived from Botswana Youth Risk Behavior Surveillance survey conducted in Botswana in 2009 which is a nationally representative survey of school going leaner's aged 10 to 19 years. The main objective of the survey was to assess and monitor the prevalence of key youth health risk Behaviors and related risk factors in a random sample of learners aged 10 to 19 years, in 15 Ministry of Education and Skills Development (MoESD) districts of Botswana. Both bivariate and multivariate analyses were used to analyze data in SPSS version 21 program and results were presented as odds ratios and percentages. Bivariate analyses results indicate that $10.5 \%$ of students reported that HIV transmission cannot be prevented, $13.6 \%$ thought it can be prevented by not having sex if you suspect the person has HIVIAIDS, $5.8 \%$ thought that by having only a few partners at a time would prevent transmission of HIV, $11.3 \%$ were of the view that serial monogamy would help prevent transmission, and use of condom when one feels it is important to do so score highest with $14.0 \%$. Multivariate analyses show that young children aged $10-13(\mathrm{OR}=0.689)$ who are at primary school level $(\mathrm{OR}=0.235)$ are less likely to have correct knowledge about the relationship between HIV and AIDS and also about HIV transmission and prevention than their older counterparts. Females were more likely to show negative attitudes towards PLWA than males $(\mathrm{OR}=1.3)$.
\end{abstract}

Keywords: HIV/AIDS; Youth; Knowledge; Opinions; Attitudes

\section{Introduction}

There search work on youth and HIV that has been conducted among school going children as an attempt to gauge their knowledge about HIV, attitudes towards the disease and the general sexual behavior of youth throughout the world serve to highlight the critical issues that drive the HIV epidemic [1-4]. Previous studies have focused more in measuring and classifying adolescent risk taking [5,6] for instance, observed that in communities with high servo prevalence rates, like Botswana, most new HIV/AIDS infections occur during adolescence. These studies articulate the increasing vulnerabilities of young people to HIV infection as a consequence of increased non-use of condom, multiple concurrent partnerships and related exposing behaviors such as early sexual initiation, alcohol and substance use and poor access to information and services [7-9].

It has been demonstrated that increased knowledge about AIDS is not a predictor for behavioral change [9-12] although knowledge about the disease is a prerequisite for change. In Botswana, young people continue to engage in risky sexual behavior despite widespread information and knowledge about HIV/AIDS. A more recent study by [13] found that among University of Botswana students, questions related to HIV/AIDS knowledge yielded 96\% correct responses. Despite this knowledge the study found that perceived use of testing services and condoms remain lower than might be predicted based on knowledge scores [13]. By 2008, in Botswana, only $43 \%$ of young people aged 15-24 years had comprehensive knowledge of HIV and almost half of adolescents could not correctly identify the common misconceptions about HIV and AIDS transmission [14]. Lollis et al. [7] observed the correlation between HIV/AIDS knowledge and place of childhood upbringing and the relationship between HIV/AIDS knowledge and education. Many boys and girls are not aware of the risks and vulnerabilities associated with HIV infection. Although not sufficient to change behavior, lack of knowledge is therefore one of the major factors making young people vulnerable to HIV infection [8].

Previous surveys in Botswana have also shown that HIV/AIDS awareness is generally high across the entire population spectrum and distribution of information is relatively even across the population. The Sexual Behavior of Young People in Botswana Survey of 2001and the 2005 Botswana Global School-based Student Health Survey (GSHS) were baseline surveys of knowledge, attitudes, sexual practices, and health seeking behavior among youth (10-24 years) [15,16]. In terms of knowledge and attitudes, the surveys found that young people in Botswana comparatively have a high level of adolescent sexual and reproductive health knowledge; however myths exist and there was widespread stigma regarding HIV. For example, 50\% of young people thought that kissing can transmit AIDS [15]. In terms of sexual behaviors and practices among youth, the mean age of sexual début for females was 17.2 and 16.5 for males and about $10 \%$ of young people have exchanged sex for money and/or had sex with someone ten years older [17].

Several studies have shown that young people have negative attitudes towards PLWA $[18,19]$. The problem of negative attitudes

*Corresponding author: Majelantle RG, Department of Population Studies, University of Botswana, Gaborone, Botswana, Tel: 267 3552747; E-mail: MAJELARG@mopipi.ub.bw

Received October 30, 2013; Accepted January 28, 2014; Published February 04, 2014

Citation: Majelantle RG, Keetile M, Bainame K, Nkawana P (2014) Knowledge, Opinions and attitudes towards HIV and AIDS among Youth in Botswana. J Glob Econ 2: 108. doi:10.4172/2375-4389.1000108

Copyright: (c) 2014 Majelantle RG, et al. This is an open-access article distributed under the terms of the Creative Commons Attribution License, which permits unrestricted use, distribution, and reproduction in any medium, provided the original author and source are credited. 
towards PLWA has been well researched in sub-Saharan Africa and studies carried out in the region have shown consistently that it affects both adults and youth [20-24]. In 2001, half of young children and one-fifth of older youth in Botswana believed that if someone is known to have the AIDS virus, they should be isolated even if they do not show signs of illness [25] found that HIV/AIDS-related stigma and discrimination was rampant among adolescents in Botswana and that misconceptions about HIV transmission tend to promote negative attitudes towards PLWA.

Studies done both in developed [26,27] and developing countries $[28,29]$ recognizes adolescent friendly services such as voluntary HIV counseling and testing (VHCT) as the best modem of educating adolescents about HIV and AIDS related risks. Lack of VCT information, poor quality of the services, allocation of centers, and fear of stigma or fear of VCT process are some of the reasons identified for not attending VCT services identified by youth [30]. However, other studies found that VCT uptake among young people was extremely high when offered within a community-based opt-out strategy [31]. Reports from the Botswana government indicate that utilization HIV prevention service among adolescents and young people is low, with only $6 \%$ and $10 \%$ of the boys aged $15-19$ years and $20-24$ years having been circumcised [32]. Consistent use of condoms with regular partners among young people was also reported to be too low [32]. In the BIAS III, only $17 \%$ of those aged $20-24$ yrs reported always using a condom with regular partners [14]. Though programmers for young adults and older age groups such as the routine HIV testing, ARV treatment, and condom promotion have been opined to be very good in terms of quality and coverage, reports indicate that programmers for children in adolescent ages and above are relatively weak [31].

An evaluation of the in-school Life Planning Skills component of African Youth Alliance's program in Botswana found that the program increased knowledge of HIV transmission, improved risk reduction behaviors among those who felt at risk (getting tested for HIV, reducing partners, using condoms, or abstaining), and increased both the intention to use and actual use of condoms [14]. Due to the program's success, the AYA Life Planning Skills manual was adopted for use in secondary schools nationwide in 2004. Mass media are underutilized in Botswana. There is currently no programmed that regularly provides adolescents and young people with well packaged essential information on HIV, common misconceptions, risks and vulnerabilities, and available services.

Several studies on the knowledge, opinions and attitudes of youth towards HIV/AIDS have shown that despite sufficient knowledge that youth have about HIV/AIDS, behavioral change is a major challenge [33-36]. Despite the wealth of research on youth and HIV/AIDS in Botswana there is still need to explore knowledge and attitudes as key players in our understanding of why high levels of awareness and knowledge among youth have not yielded any significant behavioral change in a sphere that has seen cultural and social dynamism overtime. It is in light of this that this paper intends to establish factors that influence knowledge, opinions and attitudes towards HIV and AIDS among youth in Botswana using data from Botswana Youth Risk Behavior Surveillance survey conducted in Botswana in the 2009. Given the high HIV prevalence in the country, it is very important to monitor the prevalence of risky health and sexual behaviors in order to tract effectiveness of prevention programs and to guide design of new behavior change interventions.

\section{Theoretical Framework}

Several theories and models have been developed and used to understand health seeking behavior and health outcomes. The common general model used for analysis of health behavior is the health belief model, which has been used as one size fits all in healthrelated studies. There are several other models/theories used for studying health behavior of individuals such as the theory of reasoned action and planned behavior; risk reduction model etc. Although these frameworks have been useful in improving our understanding of the health behaviors and outcomes, they however, have been unable to decipher the social reasoning as it relates to the spread of HIV-AIDS among young people. Hence [37] social cognitive theory appear relevant and been used to guide research relative to HIV/AIDS knowledge, attitudes and beliefs among youth, as well as the development of AIDS prevention programmers specifically designed for youth. According to Bandura [37] social-cognitive framework, people learn from a variety of experiences, including their own, and by observing the behavior of other people in their community. The theory predicts that adolescents will be better able to engage in positive self-directed change if they have knowledge about HIV/AIDS [37]. Therefore, individuals who are less knowledgeable about HIV/AIDS and those who have adverse health beliefs are most likely to engage in risky behaviors as they do not perceive themselves to be at risk [38]. More also, youth who have correct knowledge about both HIV prevention and transmission tend to hold a positive view about PLHWA and have increased chances of accessing HIV information and services. In line with Bandura [37] social-cognitive framework, this study adopts to measure the knowledge, opinions and Attitudes about HIV/AIDS based on a set of variables. The knowledge, opinion and attitudes variables are posited to be influenced by the respondent's characteristics (of sex, age, education, residence, religion, sexual initiation and number of partners). It is understood that the respondent's characteristics work to affect the respondent's reception of new knowledge and will in turn act to effect behavioral change. Acquisition of knowledge together with the respondents' background has a bearing in the changing traditional and cultural opinions about HIV and therefore their attitudes. Thus, respondent's with increased knowledge about the prevention and transmission of HIV, and with less misconceptions about HIV tend to hold positive attitudes about HIV.

\section{Materials and Methods}

Data used in this paper was derived from Botswana Youth Risk Behavior Surveillance survey conducted in Botswana in the 2009.The Botswana Youth Risk Behavior Surveillance Survey [17] is a national representative survey of school going learners aged 10 to 19 years. BYRBSS was conducted in 2009 and its main objective was to assess and monitor the prevalence of key youth health risk Behaviors and related risk factors in a random sample of learners aged 10 to 19 years, in 15 Ministry of Education and Skills Development (MoESD) districts of Botswana.

A two-stage sampling design was employed to produce a representative sample of learners. The primary sampling unit was the school and the secondary sampling unit was the classroom. The total number of classes needed was determined by dividing the sample size per district by the average number of students per class, about 40 in Botswana. Sample size calculations were based on desired levels of precision around primary outcomes of interest among both upper primary and junior and senior secondary learners. Estimates were calculated such that representative estimates of outcomes can be made 
at the district and national levels, with appropriate weighting of the districts based on population size for the national level estimates. For the learners in upper primary schools (i.e. 10-12 years), the sample size calculations was based on the precision of an estimate of the proportion of learners who do not know any of the ways of preventing HIV transmission. This proportion was estimated as $40 \%$ based on the results of the 2004 BAIS in the 10-14 year old age group. The selection of classrooms to be surveyed was obtained through the listing of the classes from each sampled primary and junior secondary school was ordered by grade (i.e. standard 5 through 7 or Form 1 through 3), from which three classes were selected at random.

While the selection of the classrooms to be surveyed within senior secondary schools was through a listing of the classes in each sample school ordered by grade (i.e. Form 4 through 5) and then two classes from each school were selected randomly. Sampled schools, classes, and learners who refused to participate in the survey were not replaced. Sampling without replacement maintains the integrity of the sample design and helps avoid the introduction of immeasurable bias into the sample.

The survey was administered in upper primary schools, in junior and senior secondary schools across 15 education districts in Botswana. A sample size of 134 upper primary learners per district was surveyed yielding a response of 2010 learners. For the learners in secondary schools the sample size calculations was based on the precision of an estimated proportion of learners aged 13-19 years who have ever had an HIV test. It was estimated that this proportion will be $11 \%$ based on the results of the 2004 BAIS in the 15-29 year old age group. A sample size of 140 junior and senior secondary learners per district was surveyed and the total number of junior and secondary school learners taking the survey was 2100 learners.

The results in this paper are based on the analysis of data using bivariate and multivariate analyses to explore the relationships between variables under investigation. During bivariate analyses sociodemographic variables were cross tabulated with dependent variables to assess their relationships. For multivariate analysis binary logistic regression model was used to provide an interpretable linear model for a binary dependent variable. All the predictor variables were entered together in the model in order to test the significance of each predictor while controlling for other predictors in the model. The data was analysed using Statistical Package for Social Sciences (SPSS) version 21 program. Bivariate results are presented as percentages and confidence intervals and logistic regression results are presented as adjusted odds ratios together with their $95 \%$ confidence intervals.

Binary logistic regression models were used to evaluate the effect of a selected array of independent variables on dependent variables relating to knowledge, attitudes and utilization of HIV testing services among youth in Botswana. The item asking the respondents about the relationship between HIV/AIDS was recorded such that correct knowledge about the relationship between HIV/AIDS was given a code of 1 and wrong knowledge was given a code of 0 . The question relating to knowledge about HIV transmission and prevention was dummycoded. The resultant variable was a binary with incorrect knowledge (code $=0$ ) and correct knowledge (code $=1$ ) about HIV transmission. There was one question on whether the respondents treated people living with HIV/AIDS in a bad way which was used as a measure of attitudes towards PLWA. Those who said yes had negative attitudes and those who said no had positive attitudes (code 1=positive attitudes and code $0=$ negative attitudes). Lastly respondent's knowledge of a place in their community where they can go for an HIV test was used to measure knowledge and utilization of HIV testing services. Four models are used, and each model analyses logistic regression coefficients for a specific dependent variable. Model 3 and 4 include dependent variables used for model $1 \& 2$ since knowledge about the relationship between HIV/AIDS(dependent variable in Model 1) and Knowledge about HIV transmission (dependent variable in model 2) and prevention have direct influence on attitudes towards PLWA and knowledge and utilization of HIV testing services.

\section{Ethical Consideration}

The study recognizes the importance of addressing ethical issues as they may arise, and ensured that all were observed during the entire research process.

\section{Amongst issues considered were the following:-}

- Ethical clearance was sought through the health research unit to do the research.

- Parental/guardian consent was sought and learners assent was obtained before being selected to participate or volunteer to take part in the study. The Research Assistants collected all letters sent to parents or guardians and verified that they were signed. The learners whose parents or guardian did not consent were then given the opportunity to answer the first part of the survey questionnaire which is mainly on their background characteristics only and the same applied to learners who did not assent even though their parents/guardians consented. Those that did not qualify to be part of the survey (under nine years old) were excused from the class rooms.

- Respondents were not coerced to take part in the study; all efforts were made to avoid deception or making false promises in order to woe participants to agree to be part of the study.

- Anonymity/Confidentiality of all information providers was assured in order to protect their individual and personal identities. Names or other personal identifiers were not recorded in any survey instruments. All survey records were marked with an automatically generated questionnaire identification number.

- The study ensured that there was neither invasion of private space, physical nor social harm to human subjects participating in the study. The learners completed a self-administered questionnaire in English during class sessions using individually issued PDA for the purpose. Each learner was able to take the survey at the same time. Because of the sensitivity of some of the questions, we expected some reactions from the learners; therefore, Class teachers were nearby to assist during and after the survey in case the need arise.

- Once the learners completed the survey, the PDA's were collected for safekeeping and all the data were downloaded into computers for storage of all data sets to avoid loss and public display of confidential information.

\section{Results}

\section{Response rates and socio-demographic characteristics}

The Botswana Youth Behavioral Surveillance Survey enrolled a total of 4289 students who were presented with a parental consent forms and 4259 were returned. Of these, 3,863 students got parent's/ guardian's consent. However, 100 students refused to take part in the 
study and of the remaining 3763 students some provided usable data with all the key variable information completed (i.e. District (3762), Age (3759), Grade (3761) and Sex (3763)), yielding a response rate of $88.3 \%$. The school response rate and the student's response rate were multiplied to provide the overall response rate of $82.1 \%$.

\section{Knowledge about HIV/AIDS}

Knowledge about the relationship between HIV and AIDS: National wide, $76.5 \%$ (3195) of students knew about the relationship between HIV and AIDS, $73.9 \%$ of male and $79.2 \%$ of female students had correct knowledge about the relationship between HIV and AIDS. This knowledge also varied by region, where $87.2 \%$ of students in Chobe had correct knowledge as compared to South East (82.6\%), North East (81.9\%), Kweneng (81.1\%) and Gantsi with $48.0 \%$ of students with the correct knowledge about the relationship between HIV and AIDS. Furthermore, a general upper trend emerges on this response variable as the age and grade of student increase. For instance the percentage of students who correctly identified the relationship between HIV and AIDS for those aged between 10 and 11 fell slightly under $60 \%$, compared with 60 to $80 \%$ for students aged 12 to 14 years and between 80 and $95 \%$ for students aged 15 to 19 years.

On the other hand, in responding to statements about the prevention of HIV transmission, a composite variable comprising seven statements on misconception (including not having sex with suspected persons, only having sex with a few partners, only having sex with one partner at a time etc) was created and another set of six was used to create a composite index on correct knowledge about the prevention of HIV transmission (including usage of condoms every time one had sex stood, abstinence, transmission from mother to child etc). The results also show that overall, $91.7 \%$ (91.1-92.3) of respondents had the correct knowledge about misconceptions about prevention of HIV transmission, 91.5\% (90.6-92.4) of males compared with $91.9 \%$ (91.1-92.7) of female students. Knowledge about misconceptions regarding prevention of HIV transmission varies by region, age and level of education.

Correct knowledge about prevention of HIV transmission is also low, for instance only $16.3 \%$ (14.1-18.4) of students possessed the correct knowledge about the prevention of HIV transmission. The percentage of males (16.1\%) (12.9-19.2) with correct knowledge about prevention of HIV transmission is slightly lower than that of females (16.4\%) (13.4-19.5)

Knowledge about prevention of HIV from mother to child: There were differences by socio-demographic variables on questions regarding knowledge about prevention from mother to child, where students in lower grades presented comparatively lower percentages than those in higher grades. National wide, $83.3 \%(80.2-86.0)$ of students knew that a pregnant woman infected with HIV can transmit the virus to her unborn child, $77.5 \%$ (73.4-81.2) of students knew that a pregnant woman with HIV can reduce the risk of transmission of HIV to her unborn child by enrolling in the PMTCT while $80.9 \%$ (77.3-84.1) of students knew that a woman with HIV can transmit virus to her new born child through breastfeeding.

There were, however, slightly higher percentages of females with the correct knowledge on all the three variables compared to their male counterparts. The percentages on these also differ by region, age and level of education, for instance students in the North East region $(86.3 \%)$ had the highest knowledge the risk of transmission and uptake of PMTCT, while $85.5 \%$ of students in Cho be region knew that a pregnant woman with HIV can reduce the risk of transmission of HIV to her unborn child by enrolling in PMTCT.

The educational region of Gantsi had the lowest percentage of students who had correct knowledge about reduction of risk transmission through enrolment of HIV positive pregnant women on PMTCT. This knowledge also vary age and grade, where younger students and students in lower grades appear to have poor knowledge on this subject.

Knowledge and utilisation of HIV testing services: National wide, $79.5 \%(76.1-82.5)(\mathrm{N}=3342)$ of students knew a place to go for an HIV test in their community, $28.8 \%(26.1-31.7)(\mathrm{N}=3413)$ of students have ever been tested for HIV, 34.4\% of students had an HIV test within the past year, $79.8 \%(75.1-83.9)(\mathrm{N}=857)$ of students knew the result of their most recent HIV test and 30.6\% (22.4-40.3) $(\mathrm{N}=609)$ of students reported that the result of their most recent HIV test was positive. Evidently, though a slightly higher percentage of males respondents have ever tested for HIV, they present low percentages about the knowledge of HIV services in the community and their utilization than their female counterpart's. The knowledge of facilities that provide HIV testing services in the community is high and varies by region, age, and educational level.

Utilization of programs that lead to behaviour change: Among the programmes that were most popular in terms of perceived Behavior change were makgabaneng (52.5\%) (48.6-56.3), talk back $(50.0 \%)$ (46.0-54.0) and Choose life (44.7\%) (40.7-48.8). There are, however, variations by background characteristics for each of these programmes. For instance there were proportionally more students in South East who felt that the Makgabaneng programme has helped them to change their Behavior; more females than males and students in higher grades than there are in other educational categories see Table 1.

There were also proportionally more students in South East who felt that the PSI "choose life" programme has helped them to change their Behavior; and students in higher grades than there are in other educational categories. Furthermore, there were proportionally more students in the North East who felt that the Talk Back programme has helped them to change their Behavior; more females than males, more 18 year olds than other age categories and more students in higher grades than there are in other educational categories.

Binary logistic regression results on knowledge about HIV/ AIDS: Binary logistic regression model was used to evaluate the effect of selected independent variables on dependent variables relating to knowledge, attitudes and utilization of HIV testing services among youth in Botswana. The model estimated regression coefficients through the maximum likelihood and the results are presented as adjusted odds ratios, together with their $95 \%$ confidence intervals.

Model 1: Logistic regression coefficients showing the likelihood that an individual youth had correct knowledge about the relationship between HIV and AIDS: The results of the first model indicate that female students are more likely to have correct knowledge about the relationship between HIV and AIDS compared to their male counterparts even though there is no statistical significance. Youth aged $13-16$ years were $31 \%$ less likely to have correct knowledge about the relationship between HIV and AIDS compared to those aged 17-19 years, and young people who were at upper primary school were $76 \%$ less likely to have correct knowledge about the relationship between HIV and AIDS compared to those who are at senior secondary school when all other independent variables are held constant. 
Citation: Majelantle RG, Keetile M, Bainame K, Nkawana P (2014) Knowledge, Opinions and attitudes towards HIV and AIDS among Youth in Botswana. J Glob Econ 2: 108. doi:10.4172/2375-4389.1000108

Page 5 of 7

\begin{tabular}{|c|c|c|c|c|}
\hline Variable & Model 1 & Model 2 & Model 3 & Model 4 \\
\hline $\begin{array}{l}\text { Sex } \\
\text { Male } \\
\text { Female }\end{array}$ & $\begin{array}{l}1.000 \\
1.085\end{array}$ & $\begin{array}{l}1.000 \\
1.122\end{array}$ & $\begin{array}{l}1.000 \\
1.140\end{array}$ & $\begin{array}{c}1.000 \\
(1.313)^{*}\end{array}$ \\
\hline $\begin{array}{l}\text { Age } \\
10-13 \\
14-16 \\
17-19\end{array}$ & $\begin{array}{c}(0.689)^{*} \\
0.812 \\
1.000\end{array}$ & $\begin{array}{l}0.906 \\
1.058 \\
1.000\end{array}$ & $\begin{array}{l}0.813 \\
0.958 \\
1.000\end{array}$ & $\begin{array}{l}1.262 \\
1.057 \\
1.000\end{array}$ \\
\hline $\begin{array}{l}\text { Education } \\
\text { Upper primary } \\
\text { Junior secondary } \\
\text { Senior secondary }\end{array}$ & $\begin{array}{c}(0.235)^{*} \\
0.746 \\
1.000\end{array}$ & $\begin{array}{c}(0.269)^{\star} \\
(0.474)^{\star} \\
1.000\end{array}$ & $\begin{array}{c}(0.565)^{*} \\
0.796 \\
1.000\end{array}$ & $\begin{array}{c}(0.317)^{*} \\
0.673 \\
1.000\end{array}$ \\
\hline $\begin{array}{l}\text { Residence } \\
\text { Urban } \\
\text { Rural } \\
\end{array}$ & $\begin{array}{l}1.000 \\
1.071\end{array}$ & $\begin{array}{l}1.000 \\
1.227\end{array}$ & $\begin{array}{l}1.000 \\
1.061\end{array}$ & $\begin{array}{c}1.000 \\
(0.724)^{\star}\end{array}$ \\
\hline $\begin{array}{l}\text { Religion } \\
\text { No religion } \\
\text { Christian } \\
\text { Other religions }\end{array}$ & $\begin{array}{c}1.000 \\
(2.026)^{\star} \\
(0.752)^{\star}\end{array}$ & $\begin{array}{c}1.000 \\
(1.468)^{\star} \\
0.924\end{array}$ & $\begin{array}{c}1.000 \\
(1.401)^{*} \\
(0.724)^{*}\end{array}$ & $\begin{array}{c}1.000 \\
(1.427)^{\star} \\
(0.658)^{*}\end{array}$ \\
\hline $\begin{array}{l}\text { Have you ever had sexual intercourse? } \\
\text { Yes } \\
\text { No }\end{array}$ & $\begin{array}{c}(0.777)^{\star} \\
1.000\end{array}$ & $\begin{array}{l}0.819 \\
1.000 \\
\end{array}$ & $\begin{array}{l}0.990 \\
1.000 \\
\end{array}$ & $\begin{array}{c}(0.678)^{*} \\
1.000\end{array}$ \\
\hline $\begin{array}{l}\text { Number of sex partners in the past twelve months } \\
\text { None } \\
\text { One } \\
\text { Two or more }\end{array}$ & $\begin{array}{c}1.000 \\
(1.762)^{*} \\
0.822\end{array}$ & $\begin{array}{l}1.000 \\
1.447 \\
1.903\end{array}$ & $\begin{array}{l}1.000 \\
1.287 \\
1.108\end{array}$ & $\begin{array}{c}1.000 \\
1.117 \\
(0.613)^{*}\end{array}$ \\
\hline $\begin{array}{l}\text { Knowledge about HIV transmission } \\
\text { Incorrect Knowledge } \\
\text { Correct Knowledge }\end{array}$ & & & $\begin{array}{c}(0.630)^{\star} \\
1.000\end{array}$ & $\begin{array}{c}(0.607)^{*} \\
1.000\end{array}$ \\
\hline $\begin{array}{l}\text { Knowledge about the relationship between HIV and AIDS } \\
\text { Incorrect Knowledge } \\
\text { Correct Knowledge }\end{array}$ & & & $\begin{array}{c}(0.485)^{\star} \\
1.000\end{array}$ & $\begin{array}{c}(0.602)^{*} \\
1.000\end{array}$ \\
\hline
\end{tabular}

Model 1=Knowledge about the relationship between HIVIAIDS;

Model 2=Knowledge about HIV transmission and prevention;

Model 3=knowledge and utilization of HIV testing services;

Model 4=; Attitudes towards PLWA.

* Statistically significant at $p<0.05$;

1.000 is the reference category.

Table 1: Logistic regression coefficients showing Knowledge, opinions and attitudes towards HIV and AIDS among youth.

Furthermore, youth who profess to be Christians are 2 times more likely to have correct knowledge about the relationship between HIV and AIDS compared to those who do not have any religion, whereas those who belong to any religion other than the Christian religion are $25 \%$ less likely to have correct knowledge about the relationship between HIV and AIDS. Young people who have ever had sexual intercourse were $22 \%$ less likely to have correct knowledge about the relationship between HIV and AIDS compared to those who have never had sexual intercourse, whereas those who reported one sexual partner were 1.7 times more likely to have correct knowledge about the relationship between HIV and AIDS compared to those who had no partners. Those who had multiple sexual partners were $12 \%$ less likely to have correct knowledge about the relationship between HIV and AIDS compared to those who had no partners.

Model 2: Logistic regression coefficients showing the likelihood that an individual had sufficient knowledge about HIV transmission and prevention: The results of model 2 show that there is no statistical significance between sex of the respondent and age of the respondent and whether an individual youth has sufficient knowledge about transmission and prevention of HIV/AIDS. However, individuals who are at upper primary are $73 \%$ less likely to have sufficient knowledge about HIV transmission and prevention than those who are at senior secondary school, whereas those who are at junior secondary are 53\% less likely to have sufficient knowledge about HIV transmission and prevention compared to those who are at senior secondary.
The results also show that individuals who say they belong to Christianity are 1.4 times more likely to have correct knowledge about HIV transmission and prevention compared to those who have no religion and whereas who say they belong to any other religion are $92 \%$ as likely as those who have no religion to have sufficient knowledge about HIV transmission and prevention. Whether a young person have had sexual intercourse or not, or number of sexual partners a young person has, did not have any significant influence on their knowledge about HIV transmission and prevention.

Model 3: Logistic regression coefficients showing the likelihood that an individual had knowledge of where to obtain HIV testing services: Model 3 results show no significant relationship between knowing where to obtain HIV testing services and sex, age, and place of residence. However, the results clearly shows that young people who are at upper primary are $54 \%$ less likely to know where to go for HIV testing services compared to those who are at senior secondary school. Individuals who profess Christianity are 1.4 times more likely to know where to go HIV testing services compared to those with no religion whereas those who profess other religions other than Christianity are $28 \%$ less likely to know where to obtain HIV testing services compared to those who have no religion.

Furthermore the results indicate no significant association between having had sex, number of sexual partners and whether one knows where to go for HIV testing services. Individuals who have in sufficient 
knowledge about HIV transmission and prevention are $37 \%$ less likely to know where to obtain HIV testing services compared to those with sufficient knowledge about HIV transmission and prevention, whereas those with incorrect knowledge about HIV transmission and prevention are $51 \%$ less likely to know where to go for HIV testing services.

Opinions and attitudes towards people living HIV/AIDS: National wide, $20.8 \%(18.0-24.0)$ of students reported that they view people infected with HIV in a bad way, and $72.6 \%(68.2-76.5)$ thought that a healthy looking person can be infected with HIV. The percentages between males and females show that 23.9\% (19.6-28.8) of males had negative attitudes towards people with HIV compared with $17.8 \%(14.3-22.0)$ females. The data also shows that males are more discriminatory and stigmatized people infected with HIV. Furthermore, the data shows that the Chobe region (85.4\%) presents a disproportionately higher percentage of students who knew that a healthy looking person can be infected with HIV compared with the North West region (54.0\%). These proportions also vary by age and grade, and show an incremental pattern as age and grade advances.

Model 4: Logistic regression coefficients showing the likelihood that an individual had positive attitudes towards PLWA: Results of model 4 show that there is a significant relationship between having positive attitudes and the sex of the respondent, with females 1.3 times more likely to have positive attitudes towards PLWA compared to their male counterparts. Young people who are at upper primary school are $68 \%$ less likely to have positive attitudes towards PLWA compared to those at senior secondary school, and those who stay at rural areas are $28 \%$ less likely to have positive attitudes towards PLWA compared to those who stay at urban areas.

The results also show that young people who are Christians are 1.4 times more likely to have positive attitudes towards PLWA compared to those who have no religion, whereas those who belong to other non-Christian religions are $34 \%$ less likely to show positive attitudes towards PLWA compared to those with no religion. Individuals who had ever had sex were $68 \%$ as likely as those who have never had sexual intercourse to show positive attitudes towards PLWA whereas those had multiple sexual partners were $61 \%$ as likely as those who no partner to have positive attitudes towards PLWA. Furthermore, the results indicate that young people who have insufficient knowledge about HIV/AIDS transmission and prevention are 39\% less likely to have positive attitudes towards PLWA compared to those who have sufficient knowledge about HIV transmission and prevention. Individuals who have incorrect knowledge about the relationship between HIV and AIDS are $40 \%$ less likely to have positive attitudes towards PLWA compared to those who have correct knowledge about the relationship between HIV and AIDS.

\section{Discussion and Conclusion}

This study found out that misconceptions about HIV transmission continue to exist among learners and these vary by sex age and level of education. These results are consistent with [3] where false perceptions and beliefs about HIV transmission were likely to sustain the spread of HIV/AIDS among young people in the Ejura-Sekyedumase district of Ghana. This clearly shows that there is a crucial need for young people to be continuously provided with HIV education and relevant prevention messages to help protect themselves from infection and remove the misconceptions as evidenced by the prevailing misconceptions. It is therefore important to urgently implement strategies that will improve HIV infection risk perception and aversion by intensifying education and targeting relevant prevention messages to help learners protect themselves from infection from an early age.

School based intervention programs intended to lead to Behavior change are being utilised by learners with most popular being makgabaneng, talk back and Choose life. The uneven distribution of learner programme utilisation is likely to be reflective of school time commitment to the programmes. Despite the prevalence of the intervention programmes, the baseline study reveals many learners aged 10 to 19 years continue to engage in Behaviors that place them at risk for STIs including HIV and other leading causes of morbidity and mortality.

For the successful delivery of HIV counselling and testing it important that young people are aware of the availability of these services. The data from BYRBSS indicate that although 80 per cent knew of a place to go for an HIV test only a third have ever tested and among those who tested about 80 per cent know of their results and one third reported a positive HIV test. The statistics obtained from the survey on self-reports about students HIV status appear dubious given that the prevalence of HIV among respondents aged 10-14 years and 15-19 years in BAIS II \& III is very low. The prevalence of HIV among respondents aged 10-14 years and 15-19 years in 2004 was estimated at $3.9 \%$ and $6.5 \%$ respectively. The HIV prevalence appear to have declined in 2008 with $3.5 \%$ of respondents aged 10-14 years who were positive and only $3.7 \%$ of respondents aged $15-19$ years. It follows from these observations that the self-reports on HIV status were either exaggerated or students who tested did so because they were already sick from HIV/AIDS opportunistic infections. It should also be noted that a majority of learners who tested did so because they were worried about their health and it is most likely that those who tested positive were born to HIV positive mothers (and got the virus through vertical transmission) since they do not appear to follow the national pattern and should therefore be disregarded. These results could also be indicative of lack of understanding of HIV infection in general, and as such students may have construed unfamiliar signs and symptoms to be due to HIV infection. This called for a detrainment of self-reports in studies of this kind in the future.

\section{References}

1. Bowie C, Ford N (1989) Sexual behaviour of Young People and the Risk of HIV Infection. J Epidemiol Commun H 43: 61-65.

2. Sharma AK, Sehgal VN (1998) Knowledge, attitude, belief and practice (K.A.B.P) study on AIDS among senior secondary students. Indian J Dermatol Venereol Leprol 64: 266-269.

3. Hall HI, Ruiguang S, Rhodes P, Prejean J, Qian A, et al. (2008) Estimation of HIV incidence in the United States. JAMA 300: 520-529.

4. Buzwell S, Rosenthal I (1996) Constructing a Sexual Self-Adolescents Self Perception and Sexual Risk Taking. Journal of Research on Adolescents 6: 489-513.

5. Venier JL, Ross MW, Akande A (1998) HIVIAIDS Related Social Anxieties in Adolescents in three African Countries. Soc Sci Med 46: 313-320.

6. Urmil AC, Dutt PK, Sharma KK, Ganguly SS (1989) Medico profile of male teenager STD patients attending clinic in Pune. Indian J Public Health 4: 176 182.

7. Lollis CM, Johnson EH, Antoni MH, Hinkle Y (1996) Characteristics of AfricanAmericans with multiple risk factors associated with HIVIAIDS. Journal of Behavioural Medicine 19: 55-71.

8. Thupayagale-Tshweneagae G (2010) HIV-Positive adolescents to prevent stigmatization in Botswana, International Nursing Review 57: 260-264.

9. Central Statistics Office (2009) Wise-up campaign. Government printers, Gaborone. 
Citation: Majelantle RG, Keetile M, Bainame K, Nkawana P (2014) Knowledge, Opinions and attitudes towards HIV and AIDS among Youth in Botswana. J Glob Econ 2: 108. doi:10.4172/2375-4389.1000108

10. Nzyoko S, Lurie P, McFarland W, Leyden W, Nyamwaya D, et al. (1997) Adolescent Sexual Behaviour Along the Trans-African Highway in Kenya. AIDS 11: $21-26$.

11. Kapiga S, Nachtigal G, Hunter D (1991) Knowledge of AIDS among Secondary School Pupils in Bagamoyo and Dar Es Salaam, Tanzania. AIDS 5: 325-328.

12. Hingson R, Strunin L (1992) Monitoring Adolescents Responses to the AIDS Epidemic; Changes in Knowledge, Attitudes, Beliefs and Behaviours. SAGE Publications 14: 17-33.

13. Stephens LL, Bachhuber MA, Seloilwe E, Gungqisa N, Mmelesi M, et al. (2012) HIV-Related knowledge, attitudes, and practice among educated young adults in Botswana. J AIDS HIV Res 4: 159-164.

14. Siegel D, Lazarus N, Krasnovsky F, Durbin M, Chesney M (1991) AIDS Knowledge, Attitudes and Behaviour Among Inner City, Junior High School Students. Journal of School of Health 61: 160-165.

15. Centers for Disease Control and Prevention (2012) Youth Risk behavior surveillance-2009. Surveillance Summaries, MMWR 59: 5.

16. http://www.unicef.org/evaldatabase/files/BTW_2001_01.pdf

17. http://www.cdc.gov/gshs/countries/africa/botswana.htm

18. http://photos.state.gov/libraries/botswana/19452/pdfs/First\%20Botswana\%20 Youth\%20Risk\%20Behavioural\%20Surveillance\%20Survey.pdf

19. Khan $H$, Ishaq $M$, Khan $H$, Ishaq $T$ (2008) Knowledge and attitude of students regarding HIVIAIDS in Peshawar University. Journal of the Pakistan Medical Association 33: 18-21.

20. Aggleton P (2000) Comparative analysis: ResearchStudiesFromIndia and Uganda, HIV \& AIDS related Discrimination, Stigmatization and Deniel, Geneva, Switzerland.

21. Busza J (1999) LiteratureReview: Challenging HIV Related Stigma and Discrimination in South East Asia: Past Successes and Future priorities. Population Council Horizons.

22. International Center for Research on Women (2002) HIVIAIDS, Gender and Young People.

23. Gilmore N, Somrville MA (1994) Stigmatization, Scapegoating and Discrimination in Sexually Transmitted Disease :Overcoming 'them' and 'Us'. Social Science and Medicine 39: 1339-1358.

24. Goldin C (1994) Stigmatization and AIDS : Critical Issues in Public Health Social Science and Medicine 39 : 1359-1366.

25. Letamo G (2004) HIV/AIDS-related Stigma and discrimination among adolescents in Botswana. African Population Studies 19: 191-204.
26. Bandura A (1989) Perceived self-efficacy in the exercise of control over AIDS infection. In Primary Prevention of AIDS: Psychological Approaches. Sage Publications Inc, California, USA.

27. Goodman E, Cohall AT (1989) Acquired Immunodeficiency syndrome and adolescents: Knowledge, attitudes, beliefs and behaviors in a New York City adolescent minority population. Pediatrics $84: 36-42$

28. Mwaakatobe KB (2007) use of HIVIAIDS counselling and testing services among young people in Tanzania: A case study of Kinondoni District. Institute of General Practice and Community Medicine. Section for International Health, University of Oslo, Oslo, Norway.

29. Tebourski F, Ben Alaya D (2004) Knowledge and attitude of high school student regarding HIVIAIDS in Tunisia: does more knowledge lead to more positive attitude? J Adolesc Health 34: 161-164.

30. Mbago MC, Sichona FJ (2003) Correlates of knowledge of prevention of sexually transmitted diseases among primary school pupils in Tanzania. Int $J$ STD AIDS 14: 596-600.

31. Baisley K, Doyle AM, Changalucha J, Maganja K, Watson-Jones $D$, et al. (2012) Uptake of Voluntary Counselling and Testing among Young People Participating in an HIV Prevention Trial: Comparison of Opt-Out and Opt-In Strategies. PLOS ONE 7.

32. (2009) Wise up Campaign Framework. Botswana Government.

33. Mwandira JHG (2008) A comparative study of effectiveness of Youth Pee HCT Counselors and Adult counselors in promoting uptake of HIV counseling and testing among the youth in Lilongwe District, Malawi. College of Medicine University of Malawi, Malawi.

34. Jichuan C (2003) Knowledge and Behaviors about AIDS/STD among Students of Ningde Teachers' College. Chinese Journal of Health Education 11: 853854

35. Kamala BA, Aboud S (2006) Knowledge, attitudes and practices on HIV prevention among secondary school students in Bukoba Rural Kagera Region,Tanzania. Medical Students Journal 14: 14-18.

36. Basset M, Sheman J (1994) Female Sexual Behaviour and the Risk of HIV Infection: An ethnographic Study in Harare, Zimbabwe. Women and AIDS Research Programme Report, Washington DC, USA

37. Bandura A (1986) Social Foundation of Thought and Action: A Social Cognitive Theory. Prentice Hall, Englewood Cliff, New Jersey, USA

38. Lau T, Tsui HY (2005) Discriminatory attitudes towards people living with HIV AIDS and associated factors: a population based study in the Chinese general population. Sexually Transmitted Infections 81: 113-119. 